Industrial Health, 1979, 17, 21.

\title{
HOST AND AGENT FACTORS MODIFYING METABOLISM OF TRICHLOROETHYLENE
}

\author{
Hiroko NOMIYAMA and Kazuo NOMIYAMA \\ Department of Environmental Health, Jichi Medical School \\ Minamikawachi-machi, Tochigi-ken 329-04, Japan
}

(Received April 9, 1979)

\begin{abstract}
An apparent difference in trichloroethylene metabolism was observed between animals; human, rabbit and rat exposed to trichloroethylene. Rats metabolized the substance most rapidly, while metabolism in human proceeded at the slowest rate. The ratio of trichloroethanol to trichloroacetic acid, both the main metabolites in urine, was the largest in rabbit and the smallest in human.

There was not observed a significant sex difference in trichloroethylene metabolism in rat, while there seemed to exist the age difference in trichloroethylene metabolism in rat though not significant.

The metabolic pathway of trichloroethylene in rats did not alter with the size of trichloroethylene intraperitoneally injected at dose levels of $22-368 \mathrm{mg} / \mathrm{kg}$. This might suggest to establish the maximum allowable concentration of trichloroethylene in the working environment from the viewpoints other than the altered metabolic pathway of trichloroethylene with the difference dose level. It was probably due to the physical mechanism that the ratio of total trichloro-compounds in urine to the dose of trichloroethylene decreased with the increase of dose.
\end{abstract}

Physiological factors have been reported to modify the metabolism of organic solvents. For example, females are more susceptible to benzene than males, because females produce much of the toxic intermediate, pyrocathechol, than do males ${ }^{1}$. Other factors such as pregnancy, nutrition and labour conditions also affect the individual susceptibility to benzene ${ }^{2)}$. The main metabolites of trichloroethylene have been reported to be trichloroethanol and trichloroacetic acid, both of which were expressed as total trichloro-compounds ${ }^{3)}$. Since Tanaka and Ikeda $(1968)^{4)}$ reported the altered metabolism of trichloroethylene in human with the different dose level, there have been some discussions on factors modifying the metabolism of trichloroethylene ${ }^{5 \sim 7)}$, on which the present authors will discuss again based on the animal data. Furtheremore, the meaning of these results on the maximum allowable concentration will be discussed.

\section{MATERIALS AND METHODS}

For the study of species difference, human being, rabbit and rat were employed. Data on human, rabbit and rat exposure were partly cited from Nomiyama and Nomi- 


\section{H. NOMIYAMA et al.}

yama $^{5,7}$. Five male students were exposed to 250 to 380 (mean 315) ppm trichloroethylene in an exposure room $\left(60 \mathrm{~m}^{3}\right)$ for 160 minutes (equivalent to $25 \mathrm{mg} / \mathrm{kg}$ intake of trichloroethylene ${ }^{5)}$ ). Whole urine was collected every 12 hours for 6 days. Three male rabbits of Japanese white strain weighing $2.5 \mathrm{~kg}$ were injected intraperitoneally with $500 \mathrm{mg}$ trichloroethylene $(200 \mathrm{mg} / \mathrm{kg})$. Whole urine was collected using a metabolic cage and a bladder catheter at $12 \mathrm{hr}$ intervals for 4 days. Five male rats of Holtzman strain weighing $200 \mathrm{~g}$ were given intraperitoneally $10 \mathrm{mg}$ trichloroethylene $(50 \mathrm{mg} / \mathrm{kg})$. Twenty four $\mathrm{hr}$ urines were collected for 3 days usingea metabolic cage.

For the study on sex and age difference, 15 rats of Holtzman strain (5 each rats for 8 week old male, 8 week old female and 4 week old male groups) were given $10 \mathrm{mg}$ trichloroethylene intraperitoneally; urine samples were collected in metabolic cage at 24 $\mathrm{hr}$ intervals for 3 days.

For study of different dose levels, 16 male rats of Holtzman strain weighing $200 \mathrm{~g}$ were divided into 4 groups of 4 each which were injected with $22,74,221$ or $368 \mathrm{mg} / \mathrm{kg}$ trichloroethylene intraperitoneally. Urine samples were collected at $3,6,12,36$ and 48 $\mathrm{hr}$ after the injection.

Total trichloro-compounds, trichloroacetic acid and trichloroethanol in these urine samples were determined by a modification of the method of Seto-Schultze ${ }^{4)}$.

\section{RESUlts}

\section{Animal Species}

As shown in Fig. 1, urinary excretion of total trichloro-compounds decreased exponentially with observed period in human, rabbit and rat. Rates of decrease differed among animal species; in human it was very slow and a large amount was still detected 6 days after exposure. In rat the rate of decrease was fast and total trichloro-compounds was barely detected over 4 days. The decreasing rate of trichloroacetic acid was extremely slow.

Trichloroethanol decreased as fast as total trichloro-compounds except in rat, in which urine trichloroethanol was not detected over 2 days. The ratio of trichloroethanol to trichloroacetic acid was found to decrease rapidly with time in all 3 animal species.

Accumulated urinary excretion of trichloro-compounds, trichloroacetic acid and trichloroethanol, and the ratio of trichloroethanol to trichloroacetic acid are listed in Table 1. The ratio of trichloroethanol to trichloroacetic acid indicated a significant difference in trichloroethylene metabolism between 3 animal species. In rabbits the major metabolite was trichloroethanol and the minor trichloroacetic acid, while in human ?the reverse was true.

\section{Sex and Age}

A significant difference in trichloroethylene metabolism with time after trichloroethylene administration were not observed between sex or age as shown in Fig. 2. 
FACTORS MODIFYING TRICHLOROETHYLENE METABOLISM
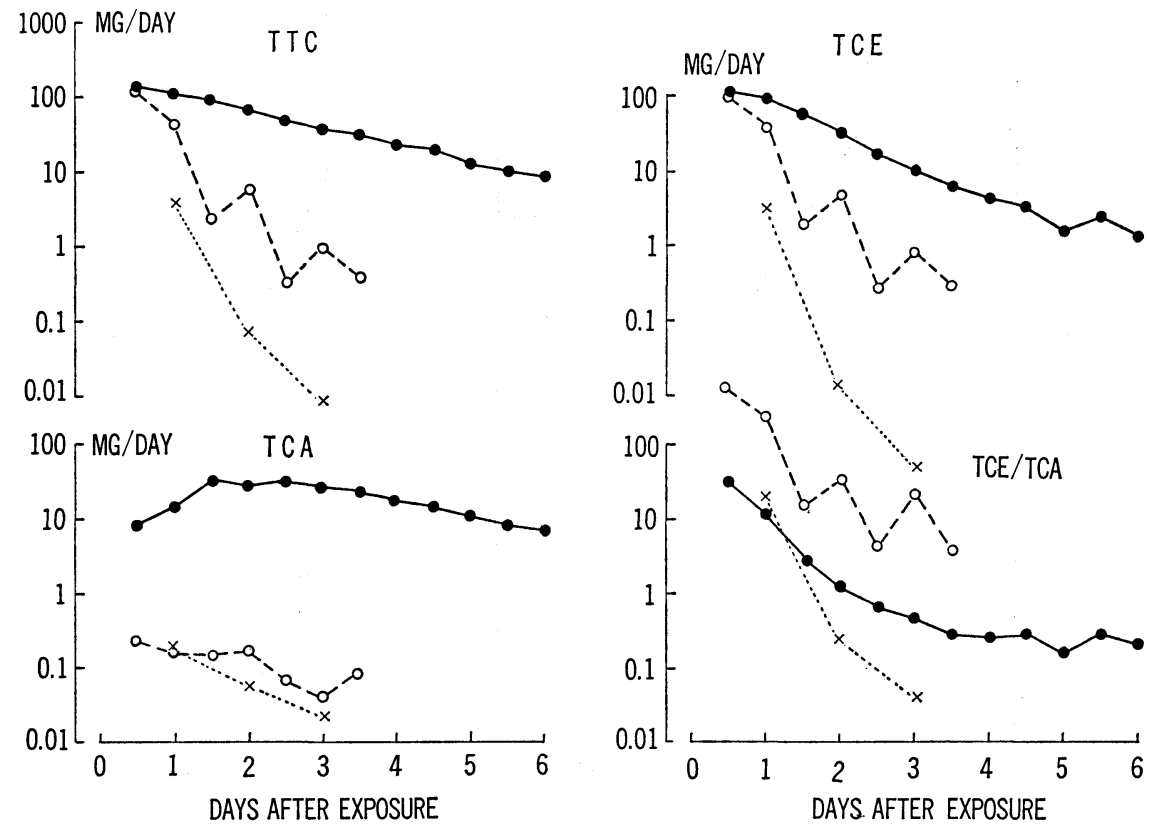

Fig. 1. Species difference in urinary excretion of trichloroethylene metabolites after exposure to trichloroethylene. Dots, circles and crosses represent human, rabbit and rat data, respectively. TTC, TCA, TCE and TCE/TCA represent total trichloro-compounds, trichloroacetic acid, trichloroethanol and the ratio of trichloroethanol to trichloroacetic acid, respectively.

Table 1. Animal species difference in accumulated urinary excretion of trichloroethylene metabolites in human, rabbit and rat.

\begin{tabular}{llrrr}
\hline \multicolumn{1}{c}{ Trichloroethylene } & & \multicolumn{3}{c}{ Species } \\
\cline { 3 - 5 } \multicolumn{1}{c}{ Metabolites } & & Human & \multicolumn{1}{c}{ Rabbit } & \multicolumn{1}{c}{ Rat } \\
\hline Total Trichloro-Compounds & $(\mathrm{mg})$ & $597.3(212.0)$ & $174.3(13.8)$ & $2.65(2.13)$ \\
Trichloroacetic Acid & $(\mathrm{mg})$ & $221.4(111.0)$ & $0.9(0.4)$ & $0.21(0.05)$ \\
Trichloroethanol & $(\mathrm{mg})$ & $343.8(111.1)$ & $157.0(14.7)$ & $2.23(1.96)$ \\
\hline \multicolumn{1}{c}{ Trichloroethanol } & & $1.90(0.97)$ & $206.6(75.0)$ & $12.45(13.58)$ \\
\hline Trichloroacetic Acid & & & & \\
\hline
\end{tabular}

Numbers express average values and those in blanket standard deviation.

As to the accumulated urinary excretion of trichloroethylene metabolites in 3 days after trichloroethylene administration, 8-week-old female rat was found to excrete more metabolites in urine than 4 -week-old male rat. The differences in the ratio of trichloroethanol to trichloroacetic acid were not significant, but 4-week-old group showed the highest ratio. 


\section{H. NOMIYAMA et al.}
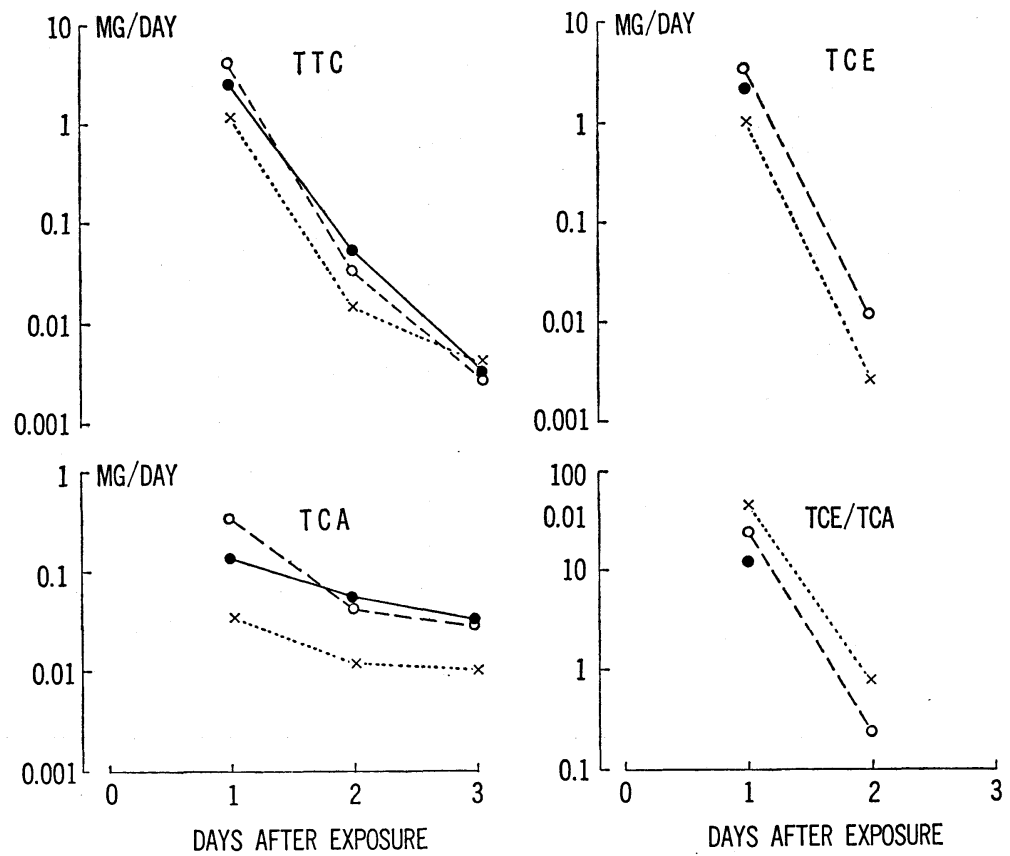

Fig. 2. Urinary excretion of trichloroethylene metabolites after exposure to trichloroethylene in rat. Dots, circles and crosses represent 8 -week-old male rats, 8 -week-old female rats and 4 -week-old male rats, respectively.

Table 2. Accumulated excretion of trichloroethylene metabolites in 48 hours after trichloroethylene administration in rat in sex and age

\begin{tabular}{|c|c|c|c|c|}
\hline Trichloroethylene & Sex & Male & Female & Male \\
\hline Metabolites & Age & 8 Weeks & 8 Weeks & 4 Weeks \\
\hline Total Trichloro-Compounds & (mg) & $2.65(2.13)$ & $4.18(0.97)$ & $1.19(0.99)$ \\
\hline Trichloroacetic Acid & $(\mathrm{mg})$ & $0.21(0.05)$ & $0.44(0.23)$ & $0.05(0.04)$ \\
\hline Trichloroethanol & (mg) & $2.23(1.96)$ & $3.04(0.95)$ & $1.04(0.88)$ \\
\hline$\frac{\text { Trichloroethanol }}{\text { Trichloroacetic Acid }}$ & & $12.45(13.58)$ & $9.87(16.41)^{*}$ & $27.37(21.73)$ \\
\hline
\end{tabular}

Numbers in blanket express standard deviations. * An extraordinary high value in trichloroethanol/trichloroacetic acid ratio was observed with one rat, while the average for other rats was $5.54(0.39)$.

\section{Dose}

No differences were observed in the profile of excretion curves of trichloroethylene metabolites, and also of the changes in the ratio of trichloroethanol to trichloroacetic acid with time after intraperitoneal administration of $22,74,221$ or $368 \mathrm{mg} / \mathrm{kg}$ trichloroethylene.

Accumulated urinary excretion of trichloroethylene metabolites increased almost pro- 

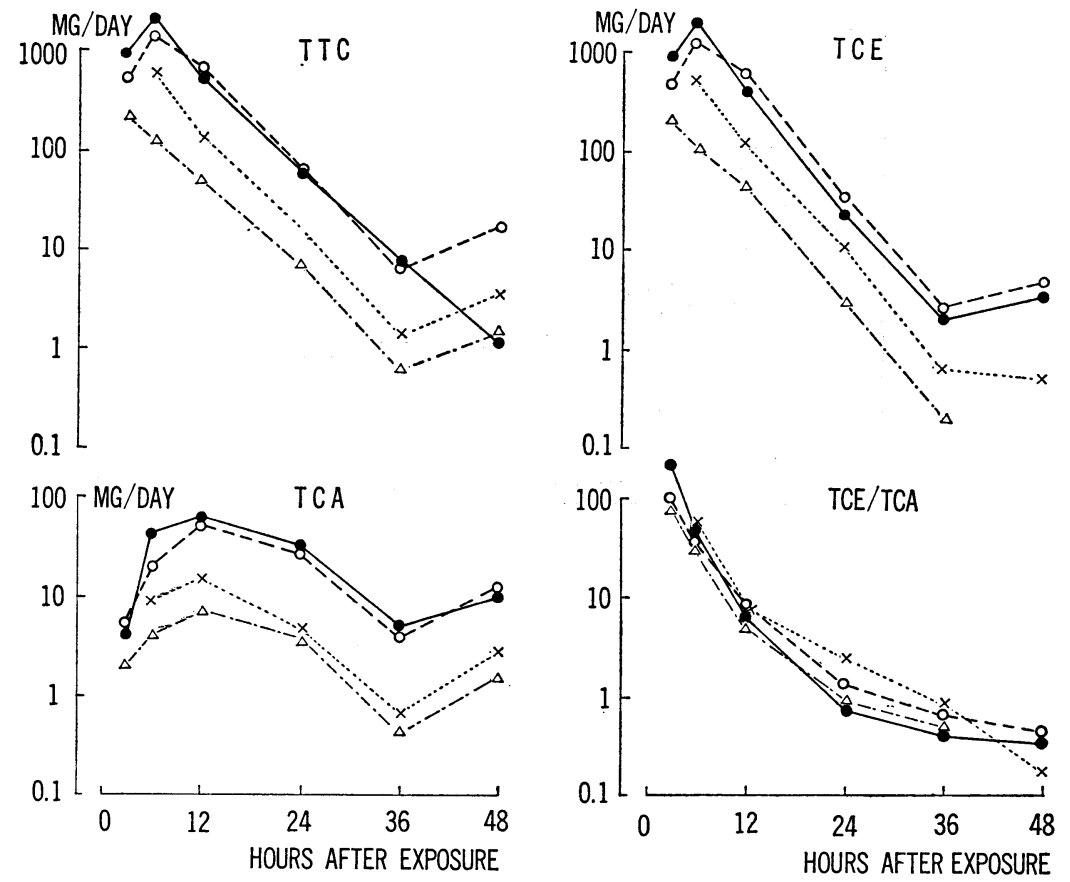

Fig. 3. Dose difference in urinary excretion of trichloroethylene metabolites after exposure to trichloroethylene in rat. Dots, circles, crosses and triangles represent $367,221,74$ and $22 \mathrm{mg} / \mathrm{kg}$ groups, respectively.

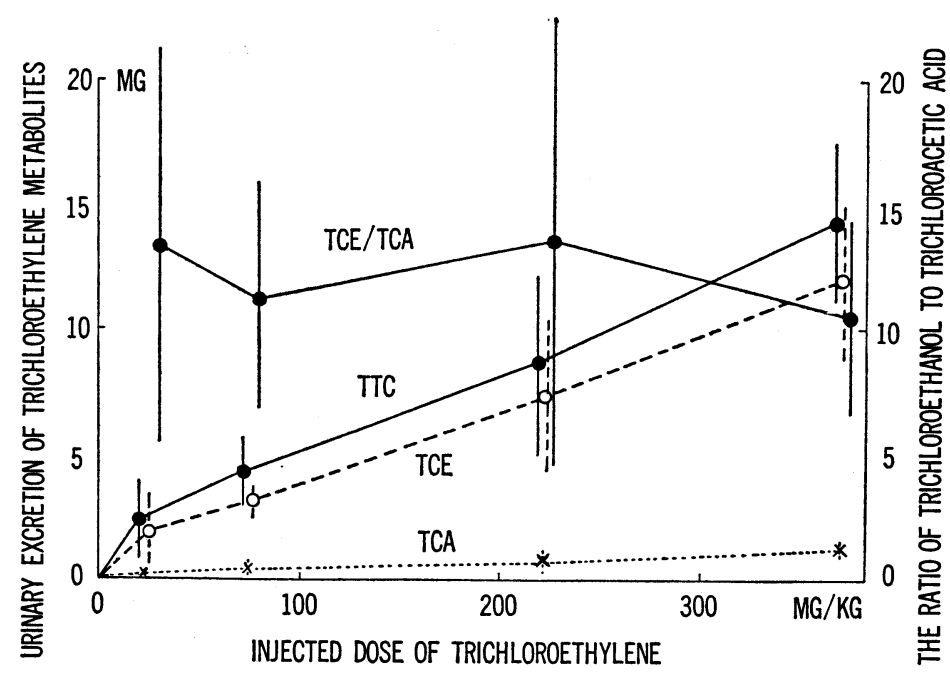

Fig. 4. Relationship between injected dose of trichloroethylene and accumulated urinary excretion of trichlorethylene metabolites in 48 hours after the injection in rat. Vertical bars represent one standard deviations. 


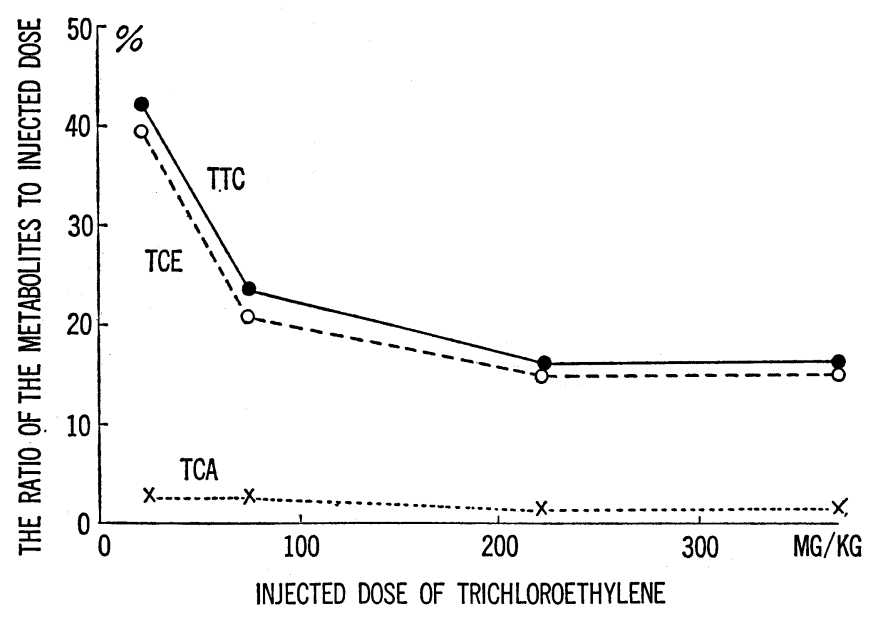

Fig. 5. Relationship between injected dose of trichloroethylene and the ratio of trichloroethylene metabolites to the injected dose of trichloroethylene in rat.

portionally to the administered dose of trichloroethylene, and the ratio of trichloroethanol to trichloroaceitic acid remained unchanged regardless the administered dose as shown in Fig. 4. The ratio of trichloroethylene metabolites to the administered dose of trichloroethylene decreased from $42 \%$ to $16 \%$ with the increase of dose of trichloroethylene as shown in Fig. 5.

\section{Discussion}

There may be some critiques addressed to the present paper that comparison between human and animals is illegal on account of different routes of trichloroethylene uptake which may decisively influence the ratio of trichloroethanol to trichloroacetic acid. However, Ikeda and Ohtsuji (1072)9) already demonstrated that the metabolism of inhaled and intraperitoneally administered trichloroethylene was the same in rat, that is, the administration route of trichloroethylene did not modify the metabolism of trichloroethylene in rat. Therefore, the present authors believed it not illegal to compare the metabolism of trichloroethylene in 3 animal species regardless the different routes of administration. The present authors gave trichloroethylene to 3 animal species in relatively a small dose levels of 25 to $200 \mathrm{mg} / \mathrm{kg}$. And as already mentioned above, the significant difference in trichloroethylene metabolism was found among human, rabbit and rat. However, this seemed to be modified by the life span of the animals. The biological half time of urinary excretion of total trichloro-compounds $(\tau=1 / 2)$, which was calculated from Fig. 1 , varied directly with the life span of the animals; the longer the life span, the slower the fall in the excretion curve (Table 3). 


\section{FACTORS MODIFYING TRICHLOROETHYLENE METABOLISM}

Table 3. Relationship between life span and biological half time of total trichlorocompounds in urine $(\tau 1 / 2)$ of human, rabbit and rat.

\begin{tabular}{lccc}
\hline Species & $\begin{array}{c}\tau 1 / 2 \text { of Total Trichloro- } \\
\text { Compounds in Days }\end{array}$ & $\begin{array}{c}\text { Life } \\
\text { in Years }\end{array}$ & \begin{tabular}{c}
$\tau 1 / 2$ \\
\cline { 3 - 4 }
\end{tabular} \\
\hline Human & 1.33 & 70 & 0.019 \\
Rabbit & 0.36 & 6 & 0.060 \\
Rat & 0.22 & 3 & 0.074 \\
\hline
\end{tabular}

Although a significant difference in trichloroethylene metabolism was observed in human ${ }^{5)}$, no sex difference was found in rat. That fact quite accorded with the report of Ikeda and Imamura (1973) ${ }^{8)}$ in rats exposed to $100 \mathrm{ppm}$ trichloroethylene vapour.

Young animals seemed to excrete rather small trichloroethylene metabolites into urine although the same amount of trichloroethylene was intraperitoneally administered. The mechanism is still unclarified.

Ikeda et al. $\left.(1972)^{8}\right)$ claimed that urinary excretion of trichloroacetic acid both in human and in rat did not increase any more at the exposure level of over $50 \mathrm{ppm}$ trichloroethylene, that is, the ratio of trichloroethanol to trichloroacetic acid increased over the level of $50 \mathrm{ppm}$. They therefore proposed $50 \mathrm{ppm}$ for the maximum allowable concentration of trichloroethylene partly because trichloroethylene metabolism altered at this level. The present authors could not confirm such an alteration in trichloroethylene metabolism at the level of $50 \mathrm{ppm}$ as shown above. Our experimental data on human also failed to support the finding of Ikeda et al. $(1972)^{6)}$ as shown previously ${ }^{7)}$. It is possible that the discrepancy between our results and those of Tanaka and Ikeda (1968) ${ }^{4}$ might arise from the fact that Tanaka and Ikeda determined the trichloroethylene metabolites in urine only for $24 \mathrm{hr}$ after trichloroethylene exposure, although the ratio of trichloroethanol to trichloroacetic acid in urine decreased with time after $24 \mathrm{hr}$ as shown in Fig. 3.

Based on the above data on the metabolism of trichloroethylene in rat and on our previous data on human ${ }^{7}$, the maximum allowable concentration of trichloroethylene in the working environment should be discussed from the viewpoints other than the altered metabolic pathway of trichloroethylene in human and/or animals.

The ratio of total trichloro-compounds in urine to the dose of trichloroethylene decreased with the increased dose level, and remained the same level at over $331 \mathrm{mg} / \mathrm{kg}$ dose level, that is, equivalent to $120 \mathrm{ppm}$ trichloroethylene exposure level, which was calculated on the report of Ikeda and Ohtsuji $(1972)^{9}$. The mechanism of the decrease in the ratio of total trichloro-compounds to the dose of trichloroethylene is not elucidated. It might be caused by the increased respiratory excretion of trichloroethylene with the dose of trichloroethylene, but not by the increased retention of trichloroethylene in fat tissue because the metabolism of trichloroethylene did not prolong with the dose of 


\section{H. NOMIYAMA et al.}

trichloroethylene as shown in Fig. 3. It is still too early, however, to take the decreased metabolism of trichloroethylene with the dose into consideration in establishing the maximum allowable concentration of trichloroethylene in the working environment.

\section{ACKNOWLEDgement}

We thank Dr. E.C. Foulkes of University of Cincinnati for correcting the manuscript. This study was supported in part by a research grant from Japan Ministry of Education, Science and Culture (1971-1972).

\section{REFERENCES}

1) Nomiyama, K. (1970). Proc. of the 16th Int. Cong. Occup. Health, Tokyo, pp. 591-592.

2) Nomiyama, K. (1970). Rodo no Kagaku (in Japanese), 25(2), 23-28.

3) Browning, E. (1965). Toxicity and Metabolism of Industrial Solvents, pp. 189-219, Elsevier, Amsterdam.

4) Tanaka, S. and Ikeda, M, (1968). Brit. J. Ind. Med. 25, 214-219.

5) Nomiyama, K. and Nomiyama, H. (1971). Int. Arch. Arbeitsmed. 28, 37-48.

6) Ikeda, M., Ohtsuji, H., Imamura, T. and Komoike, Y. (1972). Brit. J. Ind. Med. 29, 328-333.

7) Nomiyama, K. and Nomiyama H. (1977). Int. Arch. Occup. Environ. Health, 39, 237-248.

8) Ikeda, M. and Imamura, T. (1973). Int. Arch. Arbeitsmed. 31, 201-224.

9) Ikeda, M. and Ohtsuji, H. (1972). Brit. J. Ind. Med. 29, 99-104. 